\title{
Why let people die?
}

\author{
G R Gillett Ian Ramsey Centre, Oxford
}

\section{Author's abstract}

This paper concerns those patients whose brain is irreversibly damaged to the point where they will never recover significant mental life. I examine the reasons which justify the decision to withhold or discontinue active medical intervention in these patients. They involve the identity, quality of life and agency of those beings whom we value as persons.

\section{Introduction}

The diagnosis of brain death is a well established criterion for deciding that a human life has ended. In clinical practice decisions regarding resuscitation or continued life support often involve the use of this criterion. However, things are not always so clear cut. On any given night, in a number of hospitals in this country, decisions are made not to initiate or to discontinue the treatment of patients with severe brain damage. These are ethical decisions made about patients with a terrible neurological prognosis. To illustrate the problem consider an hypothetical example. A young man is admitted from a serious road accident. He reaches hospital say a half to one hour after the accident and is examined in a casualty department. He has a Glasgow Coma Scale score of 3-5 and disordered brain stem reflexes (1). His vital signs suggest brain stem damage and he has a basal skull fracture. His diagnosis is almost certainly diffuse or multifocal primary cerebral injury which may show on a CT scan as minor scattered intra-cerebral haemorrhages or only as cerebral swelling. The prognosis for this patient is grave with a high chance of his progressing to brain death (2). If brain death occurs then there are no further ethical decisions to be made, although the discussion with the relatives about what has happened will still draw upon the ethical intuitions I wish to explore. In the case of a patient who is not brain dead but is severely brain-damaged several possibilities exist. He may progress into a state in which brain stem but not higher cerebral function is

\section{Key words}

Severe brain damage; identity; quality of life; agency; the concept of a person. preserved. The classical 'persistent vegetative state' may not have developed at the time the decisions with which I am concerned are taken but he may 'recover' to a blighted dependent existence with major mental and neurological deficits and a dubious level of conscious mental life (3). I would not normally advise that an intensive resuscitation and support regime be offered to such a patient and have, on a number of occasions had to make that decision and then discuss it with the patient's relatives. Although this is a common enough situation in a busy neurosurgical unit similar decisions, based on the extent and prognosis of brain damage are made in other clinical settings: the non-evacuation of extensive intracerebral haematomata in the elderly; the non-intervention in subdural haematoma that has progressed to severe brain stem damage; the nontreatment of patients with catastrophic subarachnoid haemorrhage; and the discontinuation of life support in severe bilateral herpes encephalitis. In each case severe and irreversible brain damage warrants suspension of our normal efforts to sustain life and combat illness. The decision to discontinue active intervention in this entire group of patients can, I feel, be justified, and usually, if the situation is explained clearly, the relatives of the patient will agree with the decision that is made. Talking to relatives in such a situation is a deeply challenging experience and, although I never look forward to it, I always feel privileged to be involved as the interview unfolds.

Given that in these matters the lay person and the doctor are in substantial agreement, much of what I consider to be the presuppositions of both may well be regarded as truistic but I hope they will serve to shed some light on important features of our ethical thinking in medicine. In particular I hope to provide reasons for the abandonment of active intervention which make no appeal to consequential calculations or social utility.

\section{'Jim is not with us anymore'}

As I am often uncertain as to the religious views of the family involved in a situation where a patient is probably brain-dead I will say 'I do not know what your beliefs are, but I can assure you that, wherever he is, he is no longer here with us'. This perhaps draws heavily on the idea that the soul has departed, but I do not 
think that this is necessarily a false view. Whatever our conception of the soul, it clearly relates to the character and ethical value of the person concerned. I contend that, informal though our concept of a person is, there are three marks of the concept of a person involved in this idea. Frege's notion of 'marks of a concept' aims to pick out those properties that an entity would have if it fell under the concept in question. With certain concepts the marks will pick out a typical member of the class of items that fall under the concept and thus provide a paradigm used to guide thought in the more dubious cases. I regard our concept (person) as being paradigmatic in this sense and also as both holistic and austere in that:

(a) in elucidating it one must capture an intricate and open-ended web of facts about the properties of persons; (b) it depends upon a familiarity with the items in question and an adequate conception cannot be built out of or analysed neatly into a list of certain essential features of those items (4). Why is it this way?

As we interact with persons so we acquire the concepts and categories that we apply to our own thought and action (5) and each of us comes to appreciate himself or herself as being a member of a class of beings - with whom we are engaged and to whom we have 'reactive attitudes' (6) - a class to which we apply the term 'person'. I would regard the properties to be discussed as guiding our attitudes and inextricably bound up with the experience of mutual interaction and interpretation in which we come to understand them (7). They are not formal defining attributes which pick out just and only the members of a given class and therefore they may be ascribed by extension from the paradigm cases, to certain individuals by reason of their similarity to us or their involvement with us. I would follow David Wiggins in his misgivings about an informative or even helpful definition of (person) (8). With these provisos I will suggest that there are three marks that I take to capture the important features of our concept of a person. They are his personal identity, his quality of life and his responsibility for self. These are internally related to each other and related to our ethical attitudes to the extent that it is difficult to separate the descriptive and evaluative aspects of their content. I shall discuss them separately but the discussions will overlap.

(i) We treat a person as a being with continuity over time and, because he is now the same being as he will be at some future time, we ascribe to him an interest in his future and in what he will be like at that future time. (ii) We are concerned for the experiences of the individual involved, what-it-is-like-to-be him (9), a concern which lies at the bottom of much of our empathic morality.

(iii) A person acts and takes a role in human life and relationships in which our 'reactive attitudes' are shaped and applied.

(iv) Each person has an identity. We normally identify a person by his bodily characteristics but, having done so, regard him as being the person he is because of facts about him which are not purely physical. These are facts about his thought life and its individual character. We consider that each person thinks of himself as being a certain distinct individual, the same person in the many different experiences which comprise his life. In this we follow John Locke (10). We expect a person to be aware of his own attitudes as being his own and to demonstrate and define for himself a character. We thus come to appreciate and react to him as the individual who he is; and ground many of our moral attitudes toward him and his future on the fact that he is an objective individual with a longitudinally coherent mental life and relationships to others that enable him to develop a character and identity in the course of his life. The ability he has to express and develop his personality is crucially dependent upon the intact functioning of his brain (particularly those areas most severely damaged in trauma or anoxia/ischemia) which enables him to interact with others and the world around him in a rich and complex manner. Once this crucial enabling condition is removed we are justified in thinking that his body can no longer be seen as the locus of that activity we call the expression of personal identity. If his brain is no longer working and has no prospect of returning to an adequate level of function to support this activity, then his identity as an embodied person has been destroyed. Notice that we need to presume no metaphysical doctrine to take this view, whether his identity is manifest in some other realm is not at issue, what is clear is that in this world, and in this body, there is no preservation of personal identity beyond at most, a possible continuing vegetative function (by this I mean that level of function at which the brain continues to exhibit sufficient neural activity to support life, bodily homeostasis and reflexes but not conscious or rational activity). 'Jim is not with us anymore' captures the fact that the patient is no longer equipped to be engaged in personal life in this world.

\section{'He would never want to be a vegetable'}

The second mark of our concept of a person was the idea that a person has a certain quality of life. In this we echo an Aristotelian conception that every entity in the world has its own characteristic mode of activity. A person has a certain richness of experience in the world and the ability to be aware of that experience in a certain way. Often these things are equated with some inner or subjective aspects of experience but, as normally construed, this set of ideas involves severe conceptual problems (11). If we forsake this particular philosophical gloss on experience etc there are more everyday notions that are relevant. There is a certain unquestionable good in breathing fresh air, being active and exercising unhindered, or enjoying a good meal. These are all pleasures or goods which arise directly from the physical nature of our interaction with the world. They can be described to others but to 
be fully appreciated must be experienced 'in the flesh' as it were. These are part of our quality of life and depend upon the full exercise of our bodily faculties.

There is also a good in appreciating one's life in a certain way, pursuing certain projects and being aware of one's own development and abilities. This is a good related to my awareness of what happens to me as that awareness is informed by my character, interests and purposes. Again it depends upon the exercise of my faculties of thought and thus on the proper functioning of my nervous system. When a person is in a state which will result in brain death or persistent vegetative survival we realise that his body will never interact with the world in these ways again and that he will never have an awareness of his experiences of the type described. For this reason we, and his loved ones, quite rightly say that at most, if he does happen to be one of the survivors, he will live on as a vegetable. He will no longer manifest, in this body, the proper functioning of a sentient human being and that is a deficiency which undermines his ethical status as a person who should be kept alive. We know who he is, there is no doubt as to his physical and legal identity, but we deny that there is any meaningful conception of him living on as a person in the way that is presupposed by our ethical concerns. Neither we nor he would want him merely to be a 'vegetable'.

\section{'Well he can't say, can he?'}

We normally regard a person as morally responsible for their own life and action. We respect what Jonathan Glover calls his 'autonomy' (12). Agency conceptually involves a person acting for his own reasons (13) and we respect these reasons when we treat persons as autonomous. We ground this respect in the fact that he has thoughts about his own life based on who he is and what he values which are uniquely determined by his own first person perspective. Each person thinks about himself in a very special way and on this basis forms intentions and performs actions. These capacities set him apart from his fellows and define his character and identity. They make him the irreplaceable item in the world that he is. What is at stake in a human life is not merely biological well-being but also a vital element of self-determination. Again we have an ability which is crucially dependent upon the intact functioning of the brain. The reasoning and purposiveness which allows us to formulate and execute an intentional course of action is one of the mental abilities which most distinguish men from beasts and it depends upon a high level of integrated neural activity. In a person who is in the state we are considering we can confidently predict that the nervous system will never again sustain such activity and so we relax our ethical interest in the preservation of his life. He cannot say what he wants or intends, he never will again, so we must speak on his behalf and we do.

\section{The soul has departed}

When the Christian view of man was the accepted norm 'the soul' was the term used to designate that which essentially set man off from the beasts. This distinction was usually based on his individual destiny, his rationality, his conscious enjoyment of life, and his agency and moral responsibility. Our ethical attitudes have carried many presuppositions of this view into the present age of scientific materialism. I have here briefly sought to tease out the strands of our view of a person which capture what seemed so important about the soul. The strands isolated involve the identity of the person concerned, the quality of his life and the responsibility he has for himself. It is on these marks of the concept of a person that its ethical importance is built as I have tried to show. Once all the facts about the state of the person are clear the ethical decision follows quite naturally. It is the complexity and interrelatedness of these aspects of the life of a person that distinguish it, in various degrees from the lives of various animals. Our everyday interactions and reactive attitudes also crucially involve and contribute to these features of personal life. For those who believe that human beings can relate to God then it is these aspects of human nature which would form the basis of that relationship.

Throughout our life we retain our identity as persons, carrying with us the effects of formative influences in our subjective life history, our character, and our sense of self. In our enjoyment of life we depend upon the health and welfare of our body and on the awareness we have of that life. In our actions we depend upon our reason and our ability to be a rational locus of the origin of our own behaviour. These things constitute having a soul in this mortal life we live. When the body of a person has been plunged into a state which will no longer sustain his life as a person we might say, with complete justification, that the soul has departed, no matter what our metaphysical beliefs happen to be. Notice that, without 'fiddling about' with the definition of death, we can make the decision that this person is no longer, in any ethically interesting sense, alive. Having made that decision we no longer have in our charge a person who is a patient whom we must care for but a body in which our former patient has no further interest. (The reason I demur from saying that we should extend the definition of death to a state of irreversible coma [14] or to the persistent vegetative state is that I have not pursued the possibilities of a 'Sorites argument' once this move is made [15].) From all points of view the termination of active medical intervention is fully justified. Once that decision has been made other decisions, about his body, can be made in the light of his expressed wishes and those of his next of kin.

G R Gillett, Fellow of the Royal Australasian College of Surgeons (Neurosurgery), Research Associate, Ian Ramsey Centre, St Cross College, Oxford, and Fellow in Philosophy, Magdalen College, Oxford. 
(1) The Glasgow Coma Scale is now widely used to assess coma, especially in trauma. It was originally described by Teasdale G, Jennett B, most accessibly in Assessmenı of coma and impaired consciousness. Lancet 1974; 2: 81 .

(2) Jennett B, Teasdale G. Assessing brain damage. Fournal of neurosurgery 1979; 50: 271.

(3) One subgroup of such patients are those in 'persistent vegetative state': Jennett $B$, Plum F. Persistent vegetative state after brain damage. Lancet 1972; 1: 734.

(4) Notice that 'austere' as here used does not exclude there being identifiable features of a typical item of the type in question, it merely excludes the reduction of the concept into some combination of such properties.

(5) Donald Davidson has pointed in this direction in Thought and Talk in Inquiries into truth and interpretation. Oxford: O U P, 1984. The actual arguments are fully developed by $\mathrm{H} \mathrm{R}$ Harre in Personal being, Oxford: Blackwell, 1984.

(6) Strawson P F. Freedom and resentment. In: Freedom and resentment and other essays. London: Methuen, 1974.

(7) Wiggins D. What would be a substantial theory of truth? In: Van Straaten Z, ed. Philosophical subjects. Oxford: OUP, 1980.
(8) Wiggins D, Ramsey Centre seminar, Summer Term, Oxford 1985 and Sameness and substance. Oxford Blackwell, 1980.

(9) Nagel T. What is it like to be a bat?. In: Mortal questions. Cambridge: CUP, 1979.

(10) Locke J. Nidditch P H, ed. An essay concerning human understanding. Oxford: OUP, 1975.

(11) Wittgenstein L. Philosophical investigations I. 243-425 and Malcolm N. In: Armstrong D M, Malcolm N. Consciousness and causality. Oxford: Blackwell, 1984.

(12) Glover J. Causing death and Saving lives. Harmondsworth: Penguin, 1977.

(13) Davidson D. Psychology as philosophy. In: Essays on actions and events. Oxford: OUP, 1980.

(14) Irreversible coma is not a diagnostic term as used here but is merely a convenient term used to group together those patients who have been brain-damaged to the point where they will not regain conscious mental life.

(15) The Sorites argument is the paradox of the heap whereby, starting with a heap, for example of sand, removing an individual grain appears to make no difference but the effect of going on in the same way is to destroy the entire heap. With a brain-damaged person one could say 'But surely if he is dead when in a vegetative state just adding one more reflex won't make him alive?', and then one more response and so on. This would take another paper. 